\title{
ANALISIS PENERAPAN SYARIAT ISLAM DALAM SEKTOR PERBANKAN PASCA PELAKSANAAN SYARIAT ISLAM DI ACEH, INDONESIA
}

\section{Analysis of Islamic Shariah Application in the Banking Sector Post-Islamic Shariah Implementations in Aceh, Indonesia}

\author{
Munawar Rizki Jailani ${ }^{1}$ \\ Mohammad Taqiuddin Mohamad²
}

\begin{abstract}
The application of Shariah in general on the aspect of life is the specialty of Aceh which is entrusted by the Law of the Unitary State of the Republic of Indonesia. This study focuses on the analysis of the implementation of Shariah in the banking sector following the implementation of Islamic Shariah in Aceh. The method applied in this study uses a qualitative approach by referring to the study of the case of Shariah application in the banking sector in Aceh, whereas the research data is derived
\end{abstract}

Ph.D Candidate, Department of Shariah and Economics, Academy of Islamic Studies, University of Malaya, 50603 Kuala Lumpur, Malaysia, munawarjailani@, gmail.com

2 Senior Lecturer, Department of Shariah and Economics, Academy of Islamic Studies, University of Malaya, 50603 Kuala Lumpur, Malaysia, m.taqiuddin@, um.edu.my 
from library research, documentation and interviews with related parties in the implementation of Shariah in banking in Aceh. Then the data is processed using the content analysis method whether inductive, deductive or comparative. The findings show that the implementation of Shariah in the banking sector in Aceh has not been in line with the implementation of the overall application, there are still conventional banks that operate in Aceh. Also, the Shariah application in the banking sector is still less than those in areas who are impressed with the attention of the Aceh government. The Application of Islamic Shariah in the banking sector is still in the stage of an idea to run yet to the stage of implementation.

Keywords: Islamic Banking, Shariah, Aceh

\section{PENGENALAN}

Aceh merupakan satu-satunya negeri di Indonesia yang menerapkan Syariat Islam. Penggunaan istilah Syariat Islam merujuk kepada Undang-undang No. 44 tahun 1999 tentang penyelenggaraan keistimewaan pentadbiran Daerah Istimewa Aceh. ${ }^{3}$ Dalam fasal satu ayat (10) disebutkan bahawa Syariat Islam adalah tuntunan ajaran Islam dalam segala sektor kehidupan.

Seterusnya undang-undang tersebut diperkukuh dengan Undang-undang No. 18 tahun 2001 tentang bidang-bidang kuasa khas pentadbiran negeri Aceh. ${ }^{4}$ Selanjutnya penerapan Syariat Islam di Aceh diperkuat lagi dengan Undang-undang No. 11 tahun 2006 tentang Pemerintahan Aceh. Dalam Fasal 125 ayat (1) secara eksplisit disebutkan bahawa penerapan Syariat Islam di Aceh dilakukan secara menyeluruh dalam segala sektor kehidupan, meliputi aqidah, syariat dan akhlak. ${ }^{5}$

Sektor perbankan merupakan jantung yang mengerakkan perekonomian Aceh, sejarah perbankan di Aceh sudah dimulai sejak penjajahan Belanda di Kota Banda Aceh tepatnya pada 2 Disember 1918 dengan ditubuhkan De

3 Muslim Zainuddin et al., Problematika Hukum Sebat di Aceh (Banda Aceh: Dinas Syariat Islam Aceh, 2012), 47.

4 Abdul Majid, Syariah Islam Dalam Realitas Sosial: Jawaban Islam Terhadap Masyarakat di Wilayah Syariat (Banda Aceh: Yayasan Pena \& Ar-Raniry Press, 2007), 5.

5 Undang-undang No. 11 Tahun 2006 tentang Pemerintahan Aceh. 
Javasche Bank yang dipimpin oleh H.A Burlage. ${ }^{6}$ Kemudian, sektor perbankan di Aceh terus berjalan dengan sistem konvensional sehingga tahun 1988. Pada tahun 1989, perbankan Islam secara rasmi diperkenalkan untuk pertama kali di Aceh melalui penubuhan Bank Pekreditan Rakyat (BPR) Haruekat di kawasan Lambaroe Banda Aceh.

Seterusnya sebelum tahun 1999 (penerapan Syariat Islam di Aceh), bank Islam beroperasi berdasarkan undang-undang No. 7 tahun 1992 dan undangundang- No. 10 tahun 1998. Kedua-dua perundangan ini memberikan kedudukan kepada bank-bank Islam untuk beroperasi secara bersama-sama dengan bank-bank konvensional atau disebut dengan dual banking system. Ini bermakna perbankan konvensional dan perbankan Islam sama memiliki tempat dalam sektor perekonomian Aceh.

Melalui undang-undang No. 44 tahun $1999^{7}$ dan pengisytiharan penerapan Syariat Islam secara menyeluruh dalam segala aspek kehidupan di Aceh, bankbank konvensional perlu menukarkan operasinya ke dalam sistem perbankan Islam atau menutup seluruh cawangan di Aceh. Oleh yang demikian, kajian ini dijalankan untuk mengkaji penerapan Syariat Islam dalam sektor perbankan dilaksanakan dan bagaimana kesan pelaksanaan Syariah bagi sektor perbankan di Aceh.

\section{METODE KAJIAN}

Penulisan ini menggunakan metod kualitatif ${ }^{8}$ dengan pendekatan analisis deskriptif. Kajian ini mendeskripsikan penerapan Syariat Islam dalam sektor perbankan di Aceh pasca pelaksanaan Syariat Islam tahun 1999. Data yang digunakan dalam kajian ini terdiri daripada data primer dan data sekunder. Data primer diperolehi daripada sumber temu bual bersama pihak-pihak yang terlibat dengan penerapan Syariat Islam dalam sektor perbankan di Aceh seperti Dewan Perwakilan Rakyat Aceh (DPRA), ${ }^{9}$ kerajaan, Majelis Permusyawaratan Ulama (MPU), pegawai bank dan ahli akademik. Temu bual dijalankan pada

6 Bank Indonesia, 'Kajian Ekonomi Regional: Profil Provinsi Aceh,' laman web Bank Indonesia, dicapai pada 16 Mac 2019.

7 Undang-undang No. 44 Tahun 1999 tentang Keistimewaan Aceh.

8 Ansel Strauss dan Juliet Corbin, Dasar-dasar Penelitian Kualitatif (Yogyakarta: Pustaka Pelajar, 2003), 4.

9 Dewan Perwakilan Rakyat Aceh (Dewan Undangan Negeri atau DUN). Instituisi ini mempunyai kuasa dalam membuat dan meminda Kanun-kanun di Aceh, selain itu juga institusi memiliki kuasa dalam menyelia pelaksanaan Kanun-kanun itu sendiri. 
tahun 2015 hingga 2017. Data sekunder diperolehi dari Undang-undang Negara Kesatuan Republik Indonesia, Kanun-kanun Syariat Islam Aceh, buku-buku, akhbar dan jurnal-jurnal lain berkaitan penerapan Syariat Islam dalam sektor perbankan. Data-data yang diperolehi dari lapangan kemudian dirangkum sehingga membentuk konsep yang jelas. Seterusnya kaedah interpretasi dan analisis deskriptif kualitatif dilakukan.

\section{SYARIAT ISLAM DI ACEH}

Istilah Syariat Islam adalah frasa yang dibentuk oleh dua kata, iaitu kata Syariat dan kata Islam. Kata Syariat secara etimologis (lughawi) berasal dari Bahasa Arab iaitu "Syariah" yang mempunyai maksud tempat keluar mata air atau sumber mata air. Istilah tersebut berasal dari verba shara', yang bermaksud "menuju ke tempat mata air" atau jalan yang mesti diikuti, iaitu jalan ke arah sumber utama bagi kehidupan. ${ }^{10}$ Syariat menurut istilah mengandung makna sesuatu yang datangnya dari Allah SWT yang mesti dilakukan oleh manusia supaya kebaikan kehidupan manusia itu sendiri, baik di dunia mahupun di akhirat. Dalam konteks Islam, yang dinamakan Syariat adalah merujuk kepada apa yang terdapat di dalam firman Allah SWT melalui al-Quran dan hadis Rasulullah SAW.

Syariat sebagaimana dalam pengertian di atas, mengandungi segala ketentuan yang berkaitan dengan pengaturan semua aspek kehidupan manusia yang merupakan implementasi daripada apa yang terangkum dalam agama. Jika dikaitkan dengan kata "Islam", maka pengertian Syariat menjadi sempit, iaitu Syariat yang diturunkan kepada Nabi Muhammad SAW untuk mengimplementasikan agama yang dibawa Nabi Muhammad SAW, iaitu Islam.

Dapat disimpulkan bahawa Syariat merupakan keseluruhan peraturan atau hukum yang mengatur hubungan manusia dengan Allah SWT, manusia dengan manusia, manusia dengan alam (lingkungannya), baik yang diterapkan dalam al-Quran mahupun hadis dengan matlamat terciptanya kemashlahatan, kebaikan hidup umat manusia di dunia dan mahupun di akhirat kelak.

Di Indonesia, pengertian Syariat didapati tidak sama seperti apa yang dijelaskan dalam definisi Syariat Islam menurut pengertian para ulama. Istilah Syariat Islam lebih popular dengan istilah hukum Islam. Apabila terdapat golongan yang cenderung menerapkan Syariat Islam, maka yang

10 Ibn Manẓūr, Lisān al- 'Arab, vol. 3 (Bayrūt: Dār Șādir, 1990), 175; Muhammad Ibn Ya'qub al-F̄īūzabadī, al-Qamūs al-Muhit (Bayrūt: Dār al-Fikr, 1995), 659. 
dimaksudkan adalah "Hukum Islam" adalah seperti hukum perkahwinan Islam, hukum muamalat Islam, hukum jenayah Islam dan lain-lain. Dalam konteks ini, Syariat digunakan untuk menunjukkan hukum-hukum Islam, baik yang ditetapkan oleh al-Quran dan hadis, mahupun yang telah dicampuri oleh pemikiran manusia (ijtihad). ${ }^{11}$

Istilah Syariat Islam dalam Undang-undang Indonesia adalah tuntunan ajaran Islam dalam segala sektor kehidupan sesuai dengan Undang-undang No. 44 tahun 1999 tentang keistimewaan Aceh, yang dipinda dengan Undangundang Pemerintahan Aceh selepas Momorandum of Understanding MoU Hensilki antara Pemerintah Indonesia dan Gerakan Aceh Merdeka.

Adapun penerapan Syariat Islam di Aceh mengalami sejarah panjang. Syariat Islam sudah dikenal dan diterima oleh masyarakat sejak masa awal penyebaran Islam di Aceh. ${ }^{12}$ Nilai-nilai hukum dan norma adat yang telah menyatu dengan Syariat Islam dan menjadi pandangan hidup (way of life) bagi masyarakat Aceh. ${ }^{13}$ Menurut B.J Bollan seorang sarjana antropologi Belanda mengatakan, "Being on Aceh is equivalent to being a Muslim" (menjadi orang Aceh telah indentik dengan orang Islam). ${ }^{14}$

Sewaktu penjajahan Belanda, syariat Islam masih dipraktikkan oleh masyarakat Aceh, meskipun mengalami kemunduran dalam pelaksanaannya, Syariat Islam masih diamalkan dalam lingkup yang lebih kecil dan bukan menjadi asas negara seperti pada masa kerajaan Aceh. Pengaruh Syariat Islam terhadap hukum adat pun telah meliputi semua sektor hukum, sehingga dapat dikatakan bahawa Syariat Islam dan hukum adat telah melebur menjadi satu hukum.

Seterusnya, penerapan Syariat Islam mulai hilang selepas Aceh bergabung dengan Republik Indonesia pada tahun 1945. Syariat Islam yang sudah menjadi bahagian dalam kehidupan masyarakat mulai digantikan dengan

11 Fathurrahman Djamil, Filsafat Hukum Islam (Jakarta: Logos Wacana Ilmu, 1997), 8.

12 Yusni Saby, Apa Pentingnya Studi Aceh, dalam M. Jakfar Puteh, Sistem Sosial Budaya dan Adat Masyarakat Aceh (Yogyakarta: Grafindo Litera Media, 2012), xxxi.

13 Abidin Nurdin, "Revitalisasi Kearifan Lokal di Aceh: Peran Budaya dalam Menyelesaikan Konflik Masyarakat", Anlisis, Vol. XIII No. 1 Jun 2013, 139

14 Hansil Basri Siregar, "Lessons Learned from The Implementation of Islamic Shariah Criminal Law in Aceh, Indonesia", Jounal of Law and Religion, Vol 24, No. 1 (2008-2009), 143-176. 
hukum Negara Kesatuan Republik Indonesia. Permintaan rakyat Aceh untuk menerapkan Syariat Islam tidak pernah dihiraukan oleh kerajaan pusat sehingga mencetuskan pemberontakan rakyat Aceh terhadap kerajaan pusat.

Konflik panjang yang terjadi antara kerajaan pusat dan rakyat tidak berhenti sehingga presiden Suharto jatuh dan digantikan oleh Baharuddin Jusuf Habibi. Pada masa Habibi penyelesaian konflik Aceh dilakukan dengan pendekatan yang lebih lembut. Permintaan rakyat Aceh untuk menerapkan Syariat Islam diberikan pada tahun 1999 melalui Undang-undang No. 44 tahun 1999 tentang keistimewaan Aceh. ${ }^{15}$ Kemudian Undang-undang tersebut dipinda dengan Undang-undang No. 11 tahun 2006 tentang Pemerintah Aceh, Undang-undang ini dibuat selepas Momorandum of Understanding MoU antara Pemerintah Indonesia dengan Gerakan Aceh Merdeka (GAM) yang menjadikan kedudukan Aceh lebih berautonomi meskipun tetap berada dalam wilayah Negara Kesatuan Republik Indonesia.

Adapun format penerapan syariat Islam di Aceh memiliki keunikan tersendiri. ${ }^{16}$ Hal ini kerana Aceh bukanlah negara berdaulat, akan tetapi merupakan sebahagian daripada Negara Kesatuan Republik Indonesia. Indonesia pula bukanlah negara Islam meskipun majoriti rakyatnya beragama Islam. Oleh kerana itu, Syariat yang dilaksanakan di Aceh perlu mengikuti hukum dan undang-undang serta falsafah Negara Republik Indonesia. ${ }^{17}$ Dalam menerapkan hukuman sebat atau rejam ${ }^{18}$ misalnya, hukuman ini tidak dikenal dalam perlembagaan Indonesia dan penerapan hukuman rejam dan sebat di Aceh dinilai bercanggah dengan Undang-undang yang lebih tinggi, iaitu

15 Rifyal Ka'bah, Penegakan Syariat Islam di Indonesia (Jakarta: Rifyal Ka'bah Foundation Publisher, 2016), 13.

16 Buku Indonesia-Aceh (t.t), 13. Lihat juga, HAMKA, Sejarah Umat Islam (Singapura: Pustaka National Pte. Ltd, 1999) 796; Abdullah Ishak, Islam Nusantara (Khusunya di Tanah Melayu) (Kuala Lumpur: Badan Dakwah dan Kebajikan Malaysia, 1990), 118; A. Hasyimi, Sejarah Masuk dan Berkembangnya Islam di Indonesi (Bandung: PT. Al-Ma'arif, 1993), 221.

17 Misri A Muchsin, Penerapan Syariat Islam dalam Perspektif Historis (Banda Aceh: Dinas Syariat Islam Provinsi Aceh, 2007), 60.

18 Dalam Rancangan Kanun Jenayah Aceh yang diajukan dan telah disahkan oleh Dewan Perwakilan Rakyat Aceh (DPRA) pada tahun 2004 hingga 2009, Pasal 24 menjelaskan berkenaan hukuman rejam bagi pelaku zina. Dalam pasal tersebut dinyatakan: (1) Setiap orang yang dengan sengaja melakukan zina diancam dengan 'uqubat hudud 100 kali cambuk bagi yang belum menikah dan 'uqubat hudud 100 kali cambuk serta 'uqubat rejam/hukuman mati bagi yang sudah menikah. Gabenor Aceh, Irwandi Yusuf, menolak menandatangai Rancangan Undang-undang ini kerana menganggapnya bertentangan dengan hukum Nasional dan Internasional. Serambi Indonesia, 24-10-2009. 
Undang-undang No. 1 Tahun 1946 jo Undang-undang No. 73 Tahun 1958 tentang Kitab Undang-undang Hukum Jenayah (KUHP).

Realitinya, sepanjang pelaksanaan syariat Islam di Aceh, terdapat tujuh kes hukuman sebat yang telah dipersetujui oleh Mahkamah Agung Indonesia. Hal ini menunjukkan bahawa hukuman jenayah yang diatur berbeza atau bercanggah dengan undang-undang merupakan salah satu bahagian daripada pelaksanaan autonomi khusus di Nanggroe Aceh Darussalam.

\section{REALITI SEKTOR PERBANKAN DI ACEH}

Perkataan perbankan adalah kata terbitan daripada perkataan bank, bank berasal dari bahasa Italia, iaitu banca yang bermakna bangku. ${ }^{19}$ Dapat dikatakan demikian kerana pada abad pertengahan orang memberikan pinjaman dalam melakukan usahanya di atas bangku-bangku. ${ }^{20}$ Istilah ini kemudian mengalami evolusi sehingga digunakan untuk institusi yang mengelola pinjaman wang seperti Bank of Venice. ${ }^{21}$ Dalam Kamus Dewan bank didefinisikan sebagai institusi yang menawarkan perkhidmatan kewangan seperti jagaan wang, pertukaran mata wang, pemberian pinjaman dan terimaan bil pertukaran. ${ }^{22}$ Sementara pengertian perbankan menurut Undang-undang No. 10 tahun 1998 tentang perbankan adalah segala sesuatu yang berkaitan bank, merangkumi perlembagaan, kegiatan perusahaan, serta cara dan proses dalam melaksanakan kegiatan perusahaannya.

Sektor perbankan Indonesia mulai berkembang sejak dikeluarkan polisi "Pakjun" (Paket Kebijakan 1 Jun 1983) berkaitan dengan pengurangan kebergantungan bank awam pada kredit likuiditi Bank Indonesia bagi mendorong pergerakan dana masyarakat. Kemudian dikeluarkan Paket Oktober (Pakto) 1988, di mana Bank Indonesia memberi syarat dalam penubuhan bank baharu mesti memiliki modal sebanyak sepuluh milyar rupiah. Hal ini untuk mendorong pertumbuhan bank-bank baharu di Indonesia. Pada bulan Jun 1997, jumlah bank yang beroperasi mencapai sehingga 237 buah bank.

19 Sara Anisah, et. al., 'Analisis Istilah Perbankan Syariah dari Bahasa Arab: Tinjauan Morfologi dan Semantis,' Jurnal Arabic Learning and Teaching, vol. 2/1 (2013), 39.

20 Edi Wibowo dan Untung Hendy Widodo, Mengapa Memilih Bank Syariah (Bogor: Ghalia Indonesia, 2005), 36.

21 F.L. Garcia, Encyclopedia of Banking and Finance (Boston: The Bankers Publishing Company, 1962), 39.

22 Kamus Dewan (Kuala Lumpur: Dewan Bahasa dan Pustaka, 1994), 103. 
Perkembangan perbankan dalam dekad terakhir ini dilihat begitu pesat. Krisis ekonomi tahun 1998 hanya dipandang sebagai krisis kewangan yang menyebabkan perubahan pada kondisi perbankan Indonesia. Hal ini dapat dilihat melalui polisi pemerintah yang dikeluarkan untuk membubarkan sejumlah bank.

Adapun perbankan Islam pertama ditubuhkan di Indonesia pada tahun 1992 melalui penubuhan PT. Bank Muamalat Indonesia (BMI), ${ }^{23}$ yang sesuai akta penubuhannya pada tarikh 1 November 1991. Maka, sejak 1 Mei 1992, Bank Muamalat Indonesia (BMI) secara rasmi beroperasi dengan modal awal sejumlah Rp 106.126.382.000. ${ }^{24}$

Di peringkat awal operasinya, keberadaan bank Islam masih belum mendapat perhatian yang maksimum dalam sektor perbankan nasional. Asas perundangan bagi bank-bank Islam pada waktu tersebut hanya berlandaskan kepada undang-undang yang sangat terhad. Bahkan, hanya terdapat satu ayat sahaja dalam Undang-undang No. 7 Tahun 1992, ${ }^{25}$ tanpa sebarang penjelasan asas hukum Syariah serta jenis-jenis perusahaan yang dibenarkan. ${ }^{26}$

Bermula tahun 1998, kewujudan bank Islam telah mendapatkan perhatian daripada pemerintah dan Dewan Perwakilan Rakyat (DPR) ${ }^{27}$ Penyempurnaan undang-undang No. 7 Tahun 1992 tersebut menjadi undang-undang No. 10 Tahun 1998, secara tegas menjelaskan bahawa di Indonesia terdapat sistem dwi perbankan (dual banking system), iaitu sistem perbankan konvensional dan sistem perbankan Islam. Peluang ini disambut baik oleh masyarakat perbankan, melalui Undang-undang tersebut ditubuhkan beberapa bank Islam baru, seperti Bank IFI, Bank Syariah Mandiri, Bank Niaga, Bank BTN, Bank Mega, Bank BRI, Bank Bukopin, BPD Jabar dan BPD Aceh.

23 Sutan Remy Syahdeni, Perbankan Islam dan Kedudukan dalam Tata Hukum Perbankan Indonesia (Jakarta: Pustaka Utama Grafitri, 1999), 121.

24 M. Syafi'i Antonio, Perbankan Islam dari Teori ke Praktek (Jakarta: Gema Insani, 2001), 25.

25 Undang-undang No. 7 Tahun 1992 tentang Perbankan.

26 Dahlan Siamat, Manajemen Lembaga Keuangan (Jakarta: Fakultas EkonomiUniversitas Indonesia, 1999), 59.

27 Dewan Perwakilan Rakyat merupakan dalah salah satu institusi tinggi negara dalam sistem ketatanegaraan Indonesia yang merupakan lembaga perwakilan rakyat, seperti Parlimen di Malaysia. 


\section{ANALISIS PENERAPAN SYARIAT ISLAM DALAM SEKTOR PERBANKAN DI ACEH}

Aceh merupakan salah sebuah negeri di wilayah Negara Kesatuan Republik Indonesia (NKRI). Negeri ini memiliki keistimewaan berbanding dengan negeri-negeri lain. Antara keistimewaan tersebut adalah seperti kebenaran untuk mentadbir sendiri pemerintahan dan pelaksanaan Syariat Islam dalam segala sektor kehidupan sejak diperkenalkan Undang-Undang No. 44 Tahun $1999 .{ }^{28}$

Adapun sektor perbankan merupakan jantung yang menggerakkan perekonomian Aceh. Pelaksanaan Syariat Islam yang sudah diisytiharkan sejak tahun 1999 di Aceh belum memasuki sektor ini secara menyeluruh. Berbeza halnya dengan sektor-sektor lain, seperti sektor moral dan sektor syiar Islam, perhatian kerajaan dalam sektor-sektor tersebut sangat tinggi. Kanun-kanun Syariat Islam dalam sektor moral dan sektor syiar Islam sudah dibuat bahkan dilaksanakan. Ramai dari pelanggar kanun tegahan judi, mesum (khalwat) sudah dihukum dengan sebatan di hadapan orang ramai. ${ }^{29}$ Begitu juga dalam sektor syiar Islam, Kerajaan melalui kanun No. 11 Tahun 2002 mewajibkan kepada seluruh rakyat Aceh untuk memakai busana Islami iaitu pakaian yang menutup aurat, ${ }^{30}$ bahkan pada tahun 2018 kerajaan mewajibkan kepada anakanak kapal terbang yang turun di Aceh untuk menutup aurat sesuai dengan nilai penerapan Syariat Islam di Aceh. ${ }^{31}$

Menurut Fikri Sulaiman, ada keterlambatan kerajaan Aceh dalam menerapkan Syariat Islam dalam sektor perbankan kerana kerajaan Aceh ingin menerapkan Syariat Islam secara berperingkat sesuai dengan keperluan yang dianggap mendesak dan bidang-bidang yang menjadi fokus utama kerajaan. Kerajaan berpandangan, di peringkat awal, pelaksanaan Syariat Islam di Aceh lebih difokuskan pada dar'al-mafăsid, seterusnya pemakaian prinsip jalb almașālih. ${ }^{32}$

\footnotetext{
28 Lihat Undang-undang No. 44 Tahun 1999.

29307 Kali Hukum Cambuk Bagi Pelanggar Syariat Islam di Aceh, YouTube, https:// www.youtube.com/watch?v=rjBd7ObMLuU, dicapai pada 12 Disember 2018.

30 Kanun No. 11 Tahun 2002 tentang kewajiban penggunaan pakaian Islami

31 Kompas, 'Pramugari Wajib Berhijab di Aceh Menhub Sebut itu Suatu Syariat,' https://ekonomi.kompas.com/read/2018/01/31/143528226/pramugari-wajibberhijab-di-aceh-menhub-sebut-itu-suatu-syariat, dicapai pada 10 Disember 2018.

32 Fikri Sulaiman (Pegawai, Jabatan Dinas Syariat Islam Aceh), dalam temu bual beliau bersama penulis pada 8 Ogos 2018 .
} 
Pandangan tersebut selari dengan apa yang dikemukakan oleh Musannif, yang berpandangan penerapan Syariat Islam dalam sektor perbankan di Aceh perlu dilaksanakan secara beransur-ansur sebagaimana yang dilakukan oleh Rasulullah SAW dalam pengharaman khamar atau arak yang sudah menjadi budaya masyarakat Arab pada masa itu. ${ }^{33}$ Menurut beliau, riba dan bank konvensional sudah menjadi tradisi masyarakat Aceh sejak lama. Oleh yang demikian, sistem perbankan Islam memerlukan tempoh masa tertentu untuk mengaplikasikan syariat Islam.

Bagaimanapun usaha nyata untuk menerapkan Syariat Islam dalam sektor perbankan baru bermula sejak tahun 2014. Usaha ini dicadangkan oleh Majelis Permusyawaratan Ulama (MPU) Aceh dalam Lokakarya Muamalah pada tarikh 13-14 Mei 2014, meminta Kerajaan Aceh agar menyokong perkembangan ekonomi Islam di Aceh dan menukarkan Bank Aceh kepada Bank Aceh Syariah sepenuhnya. Hal ini sebenarnya merupakan refleksi kepada ketidaksabaran rakyat Aceh terhadap perubahan sistem ekonomi di negeri Serambi Mekkah agar menjadi sistem ekonomi yang berteraskan Syariat Islam. ${ }^{34}$

Bagi menyambut cadangan MPU tersebut, kerajaan Aceh bersama DPRA membuat kanun No. 9 Tahun 2014 tentang penubuhan Bank Aceh Syariah. Bank milik Kerajaan Aceh ini dahulunya mengamalkan dual banking system kemudian ditukar kepada bank yang menjalankan seluruh aktiviti berdasarkan nilai-nilai Syariat Islam. ${ }^{35}$

Pertukaran sistem operasi ini dilaksanakan pada 3 Oktober 2016 di Anjong Mon Mata Banda Aceh, bank kebanggaan masyarakat Aceh ini, secara rasmi bertukar nama dari PT Bank Aceh menjadi PT Bank Aceh Syariah. Dalam kesempatan tersebut Gabenor Aceh menyatakan ini sebagai momentum untuk mengukuhkan asas pelaksanaan Syariat Islam di Bumi Serambi Mekah.

Menurut Dermawan, proses penukaran Bank Aceh adalah berdasarkan kepada tiga asas utama, iaitu; asas falsafah, kerana umat Islam diwajibkan untuk menerapkan Syariat Islam dalam setiap aspek kehidupan termasuk dalam aspek ekonomi dan perbankan. ${ }^{36}$

33 Musannif Sanusi (Anggota Dewan Perwilan Rakyat Aceh), dalam temu bual beliau bersama penulis pada 16 Ogos 2017.

34 Hafas Furqani (Timbalan Dekan, Fakulti Ekonomi dan Bisnis Universiti Islam Negri Ar-Raniri, Banda Aceh) dalam temu bual beliau bersama penulis pada 12 Ogos 2017.

35 Lihat kanun No. 9 Tahun 2014 tentang pembentukan Bank Aceh Syariah.

36 Dermawan (Setiausaha Kerajaan Aceh), dalam temu bual beliau bersama penulis pada 14 Ogos 2017. 
Asas sosiologi, di mana masyarakat Aceh telah sejak dahulu menerapkan Syariat Islam dalam setiap kegiatan ekonomi. "Hal ini disebabkan oleh nilainilai Islam sudah lebih dahulu menyatu dan integral dengan setiap gerak dan nafas masyarakat Aceh, yang tercermin dari pola interaksi antara sesama warga, dan tercermin pula dalam adat istiadat dan tradisi masyarakat Aceh". ${ }^{37}$

Terakhir adalah asas perundangan, iaitu ketentuan perundang-undangan sebagai payung hukum bagi implementasi Syariat Islam, termasuk dalam bidang perbankan, antara lain Undang-undang No. 44 Tahun 1999 Tentang Penyelenggaraan Keistimewaan Aceh, Undang-undang No. 11 Tahun 2006 Tentang Pemerintahan Aceh, Kanun No. 8 tentang kewajipan kerajaan Aceh untuk bertransaksi dengan sistem perbankan Islam, khususnya kanun No. 9 Tahun 2014 Tentang Penumbuhan Bank Aceh Syariah dan rancangan kanun institusi kewangan Syariah. ${ }^{38}$

Sebenarnya penerapan Syariat Islam dalam sektor perbankan pada masa kini masih mencari model sistem perbankan yang ideal tidak bercanggah dengan undang-undang tertinggi di Republik Indonesia, selari dengan hasrat penerapan Syariat Islam di Aceh. Hal ini kerana sektor perbankan merupakan sektor yang highly regulated dan juga merupakan kuasa kerajaan pusat. Kerajaan negeri tidak mempunyai kuasa yang penuh dalam sektor ini, akan tetapi autonomi khusus dan penerapan Syariat Islam berusaha untuk menyesuaikan dengan sesuai dengan cita-cita dan matlamat Syariat Islam di Aceh. ${ }^{39}$

Perkembangan penerapan Syariat Islam dalam undang-undang berkaitan sektor perbankan di Aceh dapat dilihat berdasarkan jadual berikut:

37 Dermawan (Setiausaha Kerajaan Aceh), dalam temu bual beliau bersama penulis pada 14 Ogos 2017.

38 Kanun No. 9 Tahun 2014 Tentang Pendirian Bank Aceh Syariah.

39 Renaldi Syafriansyah (Pensyarah Universiti Islam Negri Ar-Raniry Banda Aceh), dalam temu bual beliau bersama penulis pada 18 September 2017. 


\section{Jadual 1: Undang-Undang Penerapan Syariat Islam dalam Sektor Perbankan di Aceh}

\begin{tabular}{|c|c|}
\hline Peraturan & Keterangan \\
\hline $\begin{array}{l}\text { Undang-undang No. } 44 \text { Tahun } \\
1999 \text { tentang penyelenggaraan } \\
\text { keistimewaan bagi provinsi Aceh }\end{array}$ & $\begin{array}{l}\text { Dalam Undang-undang ini disebutkan bahawa } \\
\text { Aceh diberikan keistimewaan khusus untuk } \\
\text { mentadbir kehidupan beragama, adat, pendidikan } \\
\text { dan mengambil kira peranan ulama dalam } \\
\text { pembentukan polisi kerajaan negeri, Undang- } \\
\text { undang ini meskipun tidak menyebutkan secara } \\
\text { eksplisit tentang penerapan Syariat Islam dalam } \\
\text { sektor perbankan, akan tetapi payung hukum } \\
\text { tersebut dapat dimaknai sebagai asas atau pembuka } \\
\text { jalan bagi penerapan Syariat Islam dalam sektor } \\
\text { perbankan. }\end{array}$ \\
\hline
\end{tabular}

Undang-undang No. 18 Tahun 2001 tentang otonomi khusus bagi provinsi Daerah Istimewa Aceh sebagai Naggroe Aceh Darussalam.

Undang-undang Republik Indonesia No. 11 Tahun 2006 tentang pemerintahan Aceh.
Undang-undang ini merupakan asas hukum pertama yang memperkenalkan istilah kanun bagi Peraturan Daerah ( PERDA) sebagai pelaksanaan Undang-undang di wilayah provinsi Nanggroe Aceh Darussalam dalam rangka penyeleggaraan otonomi khusus. Undang-undang ini juga hampir sama dengan Undang-undang No. 44 tahun 1999, iaitu belum menyebutkan secara terperinci penerapan Syariat Islam dalam sektor perbankan, akan tetapi menyebutkan secara umum penerapan Syariat Islam dalam semua aspek kehidupan termasuk dalam tuntunan pelaksanaan perbankan yang Islami.

Undang-undang ini merupakan rujukan bagi semua Kanun-kanun dan peraturan-peraturan yang berlaku di Aceh sekarang. Penggubalan undangundang ini adalah berdasarkan rundingan damai MoU (Momorandum of Understanding) di Helsinki antara Gerakan Aceh Merdeka dengan Kerajaan Indonesia. Dalam Undang-undang ini pun belum disebutkan secara eksplisit tentang penerapan Syariat Islam dalam sektor perbankan, akan tetapi dalam pasal 125 ayat 2 disebutkan Syariat Islam dijalankan secara menyeluruh termasuk dalam bidang muamalah dan dalam pasal 127 disebutkan bahawa Kerajaan Aceh bertanggung jawab atas penyelenggaraan Syariat Islam 
Analisis Penerapan Syariat Islam dalam Sektor Perbankan

Pasca Pelaksanaan Syariat Islam di Aceh, Indonesia

\begin{tabular}{cc}
\hline Peraturan & Keterangan \\
\hline Kanun- No
\end{tabular}

Pokok-Pokok Syariat Islam.

Kanun No. 9 Tahun 2014 tentang pembentukan Bank Aceh Syariah

Rancangan kanun Lembaga Keuangan Syariah (LKS)
Kanun ini mewajibkan kerajaan Aceh untuk melakukan transaksi dan penempatan dana pembangunan pemerintah Aceh seperti Anggaran Pendapatan Belanja Aceh (APBA) di instititusi kewangan atau bank Islam. Kewajipan ini juga berlaku kepada Kabupaten/Kota dalam ruang lingkup kerajaan Aceh. Melalui kanun ini, pemerintah Aceh secara nyata turut berperanan dalam memperkasakan institusi perbankan Islam.

Kanun ini merupakan asas dalam penubuhan Bank Aceh Syariah. Kanun ini merupakan hasrat awal spin off (pemisahan) antara bank Aceh dan anak syarikatnya iaitu bank Aceh Syariah. Kemudian kanun tersebut dibatalkan dengan kanun No. 5 tentang Pencabutan Kanun Aceh No. 9 tahun 2019, kerana pihak parlimen menginginkan agar kerajaan mengislamkan bank Aceh yang sudah sedia ada tanpa perlu menubuhkan bank Islam lain.

Rancangan Kanun ini akan mengatur sektor perbankan di Aceh yang selari dengan maltlamat penerapan Syariat Islam, iaitu dengan hanya mengkhususkan perbankan Islam sahaja yang beroperasi di Aceh. Rancangan kanun ini juga akan akan menjadi landasan bagi proses mengislamisasikan segala transaksi kewangan dan perbankan yang ada di Aceh.

Walau bagaimanapun, kesan penerapan Syariat Islam di terhadap sektor perbankan di Aceh belum dilihat secara jelas. Hal ini disebabkan masih terdapat bank-bank konvensional yang beroperasi di Aceh. Menurut data dari kerajaan Aceh, daripada 13 buah bank yang beroperasi di Aceh pada masa ini, hanya 38 peratus sahaja yang melaksanakan sistem perbankan Islam, dan selebihnya masih menjalankan sistem perbankan ribawi. ${ }^{40}$

40 Pemerintah Aceh, 'Alamat Bank Swasta di Bandar Aceh,' laman sesawang Pemerintah Aceh, https://acehprov.go.id/directory/read/164/alamat-bank-swastadi-banda-aceh.html, dicapai pada 25 Februari 2018. 


\section{Rajah 1: Institusi Perbankan di Aceh}

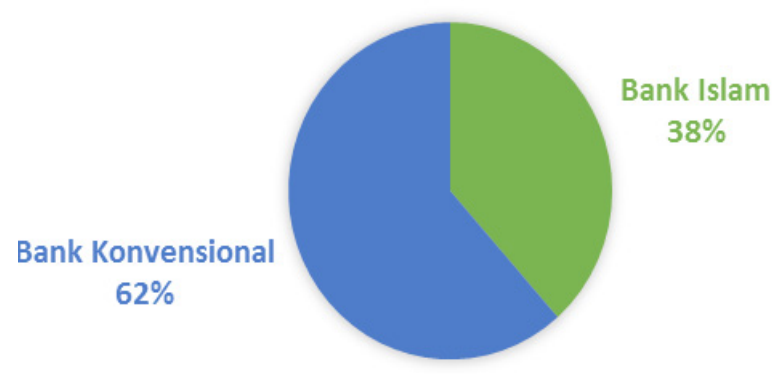

Sumber: Laman Sesawang Kerajaan Aceh (2019)

Hal ini disebabkan oleh idea pelaksanaan Syariat Islam di peringkat atasan kurang mendapat sambutan, Kerajaan Aceh dinilai kurang membuat polisi yang pro-perbankan Islam. ${ }^{41}$ Padahal, rakyat begiitu bersemangat untuk menyambut sistem perbankan Islam. Kesedaran rakyat Aceh yang tinggi untuk meninggalkan sistem ribawi dapat dilihat dari tahap pertumbuhan keseluruhan aset perbankan Islam di Aceh yang mengalami peningkatan 20\% mencapai Rp 3.77 trilion pada Oktober 2012 berbanding tahun sebelumnya yang hanya $\mathrm{Rp}$ 3.14 trilion. $^{42}$

Seterusnya, pembiayaan yang disalurkan kepada masyarakat juga meningkat kepada Rp 2.67 trilion, berbanding tahun sebelumnya hanya Rp 1.58 trilion. Demikian pula dengan asset di Bank Aceh Syariah. Unit usaha syariah Bank Aceh ini, seperti yang disampaikan oleh Pengarah Bank Aceh Syariah, iaitu Haizir Sulaiman, pada waktu ditubuhkan pada November 2004 hanya memiliki modal awal senilai Rp 5 miliar. Namun, sehingga Maret 2013 lalu, omzet yang dimiliki telah mencapai Rp 1.7 trilion dengan kadar pertumbuhan sekitar $17.5 \%{ }^{43}$

Begitu juga dengan jumlah bank Islam sebelum dan selepas pelaksanaan Syariat Islam. Meskipun jumlahnya terus bertambah, akan tetapi perlu dilihat adakah pertumbuhan tersebut berlaku disebabkan oleh kesan penerapan Syariat

41 Waisul Qarani Ali (Mantan Timbalan DPRA Aceh), dalam temu bual beliau bersama penulis pada 1 Ogos 2017.

42 Hafas Furqani (Timbalan Dekan, Fakulti Ekonomi dan Bisnis Universiti Islam Negri Ar-Raniri, Banda Aceh) dalam temu bual beliau bersama penulis pada 12 Ogos 2017.

43 Anwar Zainal (Pegawai Bank Aceh), dalam temu bual beliau bersama penulis pada 20 November 2018. 
Islam di Aceh atau ianya hanya sebagaimana pertumbuhan yang berlaku secara semula jadi seperti yang berlaku di wilayah-wilayah lain di Indonesia.

Menurut data Otoritas Jasa Kewangan (OJK), penyebaran bank awam Islam dan unit usaha bank Islam pada Oktober 2017 di Aceh mengalami peningkatan. Terdapat 37 buah Kantor Pusat Operasi (KPO) dan 102 Kantor Cabang Pembantu (KCP), jumlah ini menunjukkan lebih banyak berbanding dengan wilayah lain seperti Sumatera Utara yang hanya memiliki KPO 25 dan KCP 50, ${ }^{44}$ akan tetapi wilayah tersebut tidak melaksanakan Syariat Islam sebagaimana di Aceh.

Adapun dari segi produk perbankan Islam, didapati tiada perbezaan yang signifikan dengan produk-produk yang ditawarkan di wilayah lain yang tidak melaksanakan Syariat Islam. Menurut Anwar Zainal, hal ini disebabkan oleh kedudukan bank-bank Islam di Aceh yang masih perlu mengikuti sistem dan peraturan yang dibuat oleh Dewan Syariah Nasional (DSN). ${ }^{45}$

Sebagaimana produk pengumpulan dana di bank Aceh, produk seulanga menggunakan akad mudāarabah, produk Aneka Guna menggunakan akad mud̄ārabah, Tabungan SIMPEDA menggunakan akad muḍ̄arabah, produk TabunganKu menggunakan akad mudârabah, tabungan Haji Akbar menggunakan akad wadi'ah, Tabungan Firdaus menggunakan akad muḍārabah, Tabungan Sahara untuk simpanan Haji dan Umrah menggunakan akad wadi'ah Yad Damanah, produk Deposito Mudharabah menggunakan akad mud̄ārabah mutlaqah, Giro wadi'ah menggunakan akad wadi'ah Yad Damanah. Sedangkan dalam beberapa produk pengumpulan data di bank Aceh, pengkaji mendapati mereka masih menggunakan sistem konvensional. Contohnya produk giro bank Aceh juga menawarkan faedah dalam produk tersebut, iaitu sejumlah 1.50\%. Begitu juga dengan produk Deposito bank Aceh, didapati bank Islam tersebut masih menawarkan faedah bank sejumlah 7\%. Padahal bank Aceh telah secara rasmi menukar sistem operasinya dari bank konvensional kepada bank Islam. Anwar Zainal menyatakan bahawa akad yang dijalankan telah sesuai dengan Syariat Islam dan menggunakan akad wadi 'ah dan muḍārabah, akan tetapi belum dikemaskini ke dalam laman sesawang sahaja. ${ }^{46}$

44 Otoritas Jasa Kewangan, Statistik Perbankan Syariah Oktober 2017, 6.

45 Anwar Zainal (Pegawai Bank Aceh), dalam temu bual beliau bersama penulis pada 11 Jun 2017.

46 Anwar Zainal (Pegawai Bank Aceh), dalam temu bual beliau bersama penulis pada 11 Jun 2017. 
Adapun dalam pembiayaan, bank Aceh menawarkan beberapa produk, iaitu pembiayaan mud̄ārabah, pembiayaan mushārakah, pembiayaan murābahaha, pembiayaan Rahn, pembiayaan wakālah, pembiayaan ijārah dan pembiayaan Pensiun yang menggunakan akad muḍārabah. ${ }^{47}$

Bank Aceh juga menawarkan perkhidmatan rahn (gadai emas) atau disebut juga pembiayaan rahn yang menggunakan akad qard, rahn dan ijārah, iaitu penyerahan hak penguasaan secara fizikal ke atas barangan emas dari pelabur kepada bank sebagai jaminan atas pembiayaan yang diterima. ${ }^{48}$

Berdasarkan penjelasan di atas, pengkaji mendapati bahawa proses penerapan Syariat Islam dalam sektor perbankan sudah mula dilaksanakan. Adapun masih terdapat bank-bank konvensional di Aceh dan produk-produk bank Islam sendiri yang masih menggunakan sistem perbankan konvensional perlu mendapat perhatian yang lebih serius dari Kerajaan Aceh dan institusi terbabit dalam pelaksanaan Syariat Islam di Aceh. Hal ini merupakan amanah Undang-undang penerapan Syariat Islam secara menyeluruh dan harapan rakyat Aceh agar dapat menjalankan kehidupan beragamanya dengan baik.

\section{KESIMPULAN}

Pelaksanaan Syariat Islam yang sudah diisytiharkan sejak tahun 1999 di Aceh, sejauh ini belum memasuki pada sektor perbankan secara menyeluruh. Berbeza dengan sektor-sektor lain, seperti sektor moral dan sektor syiar Islam yang sudah mendapatkan perhatian yang besar dari Kerajaan Aceh.

Adapun dalam sektor perbankan, rakyat masih menantikan inisiatif transformasi penerapan Syariat Islam. Sistem perbankan, sebagai jantung yang menggerakkan perekonomian Aceh, masih dibiarkan berjalan dalam sistem non-Islami (ribawi). Dunia ekonomi dan usaha Aceh dibiarkan larut dalam amalan pinjam-meminjam menggunakan faedah perbankan konvensional.

Oleh yang demikian, pengkaji mencadangkan kepada pemangku kerajaan Aceh untuk memberikan perhatian yang lebih dalam menerapkan Syariat Islam dalam sektor perbankan, dengan menggubal kanun-kanun Syariat Islam dalam sektor perbankan, memperkenalkan perbankan Islam Islam kepada masyarakat dan mengukuhkan kedudukan Dinas Syariat Islam sebagai institusi rasmi dalam menerapkan Syariat Islam dalam sektor perbankan. Sehingga Aceh

47 Samsuar Abdurahman (Pegawai Bank Aceh), dalam temu bual beliau bersama penulis pada 23 September 2017.

48 Bank Aceh, http://www.bankaceh.co.id/?page_id=15, laman sesawang dicapai, 24 Ogos 2017. 
menjadi negeri yang benar-benar merepresentasikan Syariat Islam pada dunia dengan kemajuan yang diperoleh dari semua dimensi kehidupan masyarakat.

\section{RUJUKAN}

‘307 Kali Hukum Cambuk Bagi Pelanggar Syariat Islam di Aceh,' YouTube, https://www.youtube.com/watch?v=rjBd7ObMLuU, dicapai pada 12 Disember 2018.

A. Hasyimi, Sejarah Masuk dan Berkembangnya Islam di Indonesi (Bandung: PT. Al-Ma'arif, 1993).

Abdul Majid, Syariah Islam dalam Realitas Sosial: Jawaban Islam Terhadap Masyarakat di Wilayah Syariat (Banda Aceh: Yayasan Pena \& ArRaniry Press, 2007).

Abdullah Ishak, Islam Nusantara (Khusunya di Tanah Melayu) (Kuala Lumpur: Badan Dakwah dan Kebajikan Malaysia, 1990).

Abidin Nurdin, "Revitalisasi Kearifan Lokal di Aceh: Peran Budaya dalam Menyelesaikan Konflik Masyarakat”, Analisis, vol. 13, no. 1 (2013): 135-154.

Ansel Strauss dan Juliet Corbin, Dasar-dasar Penelitian Kualitatif(Yogyakarta: Pustaka Pelajar, 2003).

Bank Aceh, http://www.bankaceh.co.id/?page_id=15, dicapai pada 24 Ogos 2017.

Bank Indoensia, 'Kajian Ekonomi Regional: Profil Provinsi Aceh,' Laman Web Bank Indonesia, dicapai pada 16 Mac 2019.

Dahlan Siamat, Manajemen Lembaga Keuangan (Jakarta: Fakultas EkonomiUniversitas Indonesia, 1999).

Edi Wibowo dan Untung Hendy Widodo, Mengapa Memilih Bank Syariah (Bogor: Ghalia Indonesia, 2005).

F.L. Garcia, Encyclopedia of Banking and Finance (Boston: The Bankers Publishing Company, 1962).

Fathurrahman Djamil, Filsafat Hukum Islam (Jakarta: Logos Wacana Ilmu, 1997).

HAMKA, Sejarah Umat Islam (Singapura: Pustaka National Pte. Ltd, 1999).

Hansil Basri Siregar, "Lessons Learned from The Implementation of Islamic Shariah Criminal Law in Aceh, Indonesia", Jounal of Law and Religion, vol. 24, no. 1 (2008-2009): 143-176. 
Ibn Manẓūr, Lisān al- 'Arab (Bayrūt: Dār Șādir, 1990).

Kamus Dewan (Kuala Lumpur: Dewan Bahasa dan Pustaka, 1994).

Kompas, 'Pramugari Wajib Berhijab di Aceh Menhub Sebut itu Suatu Syariat,' https://ekonomi.kompas.com/read/2018/01/31/143528226/pramugariwajib-berhijab-di-aceh-menhub-sebut-itu-suatu-syariat, dicapai pada 10 Disember 2018.

Lexi J. Moleong, Metodologi Penelitian Kualitatif (Bandung: Remaja Rosda Karya 2002).

M. Shabri, 'Perspektif Ekonomi Islam dalam Kengentaskan Kemiskinan Rakyat Aceh,' Jurnal Ekonomi Pembangunan Bappeda Aceh, vol. 3/2 (2012).

M. Syafe'i Antonio, Bank Syariah dari Teori ke Praktek (Jakarta: Gema Insani Press, 2001).

Misri A Muchsin, Penerapan Syariat Islam dalam Perspektif Historis (Banda Aceh: Dinas Syariat Islam Provinsi Aceh, 2007).

Muḥammad Ibn Ya'qub al-Fīrūzabadī, al-Qamūs al-Muhiṭ (Bayrūt: Dār alFikr, 1995).

Muslim Zainuddin et al., Problematika Hukum Sebat di Aceh (Banda Aceh: Dinas Syariat Islam Aceh, 2012).

Otoritas Jasa Kewangan, 'Statistik Perbankan Syariah Oktober 2017,' https://www.ojk.go.id/id/kanal/syariah/data-dan-statistik/ statistik-perbankan-syariah/Pages/Statistik- Perbankan-Syariah--Oktober-2017.aspx, dicapai 9 Oktober 2019.

Pemerintah Aceh, 'Alamat Bank Swasta di Bandar Aceh,' laman sesawang Pemerintah Aceh, https://acehprov.go.id/directory/read/164/ alamat-bank-swasta-di-banda-aceh.html, dicapai pada 25 F e b r u a ri 2018.

Rifyal Ka'bah, Penegakan Syariat Islam di Indonesia (Jakarta: Rifyal Ka'bah Foundation Publisher, 2016).

Sara Anisah, et al., 'Analisis Istilah Perbankan Syariah dari Bahasa Arab: Tinjauan Morfologi dan Semantis,' Jurnal Arabic Learning and Teaching, vol. 2/1 (2013): 38-47.

Sutan Remy Syahdeni, Perbankan Islam dan Kedudukan dalam Tata Hukum Perbankan Indonesia (Jakarta: Pustaka Utama Grafitri, 1999).

Yusni Saby, 'Pelaksanaan Syari'at Islam di Aceh: Suatu Peluang dan Tantangan,' Jurnal Kanun Universiti Syiah Kuala, Banda Aceh (2002): 566-568. 


\section{Statut}

Undang-undang No. 44 Tahun 1999.

Undang-undang No. 7 Tahun 1992 tentang Perbankan.

Undang-undang No. 11 Tahun 2006 tentang Pemerintahan Aceh.

Kanun No. 9 Tahun 2014 tentang pembentukan Bank Aceh Syariah.

\section{Temu bual}

Anwar Zainal (Pegawai Bank Aceh), dalam temu bual beliau bersama penulis pada 20 November 2018.

Dermawan (Setiausaha Kerajaan Aceh), dalam temu bual beliau bersama penulis pada 14 Ogos 2017.

Fikri Sulaiman (Pegawai, Jabatan Dinas Syariat Islam Aceh), dalam temu bual beliau bersama penulis pada 8 Ogos 2018.

Hafas Furqani (Timbalan Dekan, Fakulti Ekonomi dan Bisnis Universiti Islam Negri Ar-Raniri, Banda Aceh), dalam temu bual beliau bersama penulis pada 12 Ogos 2017.

Musannif Sanusi (Anggota Dewan Perwilan Rakyat Aceh), dalam temu bual beliau bersama penulis pada 16 Ogos 2017.

Samsuar Abdurahman (Pegawai Bank Aceh), dalam temu bual beliau bersama penulis pada 23 September 2017.

Renaldi Syafriansyah (Pensyarah Universiti Islam Negri Ar-Raniry Banda Aceh), dalam temu bual beliau bersama penulis pada 18 September 2017.

Waisul Qarani Ali (Mantan Timbalan DPRA Aceh), dalam temu bual beliau bersama penulis pada 1 Ogos 2017. 
Jurnal Syariah, Jil. 27, Bil. 2 (2019) 261-280 